\title{
Standards for Low Values of Direct Capacitance
}

\section{By Charles Moon and C. Matilda Sparks}

\begin{abstract}
In the measurement of small capacitances, such as the interelectrode capacitance of vacuum tubes, standards are needed for checking the calibration of the measuring equipment. The design, construction, and measurement of a group of small primary and secondary standards of capacitance for this purpose are described, the values of which range from 0.001 to 5.0 micromicrofarads. Capacitators of $0.1 \mu \mu \mathrm{f}$ and above are of the Kelvin guard-ring type; those of $0.1 \mu \mu \mathrm{f}$ and smaller are of a new "guard-well" type, which permits the construction of primary standards for values as low as desired.
\end{abstract}

\section{Introduction}

For several years there has been a demand from industrial and governmental laboratories for testing and certifying small direct-capacitance standards for use in checking the calibration of bridges, or test sets, which in turn are used to measure the interelectrode capacitance of electron tubes. The direct capacitance (coefficient of capacitance) is the ratio of the charge on the guarded electrode to the potential of the high-voltage plate, when the shield is at the same potential as the guarded electrode. The values of the standards required range from 0.001 to $100 \mu \mu \mathrm{f}$. The work described in this paper was undertaken to supply the need for capacitance standards of $5 \mu \mu$ f and below, as larger standards can be readily measured by established methods.

The capacitors described are of the three-terminal type, consisting of a guarded electrode, a highvoltage plate, and a shield. A number of small primary standards have been built, the values of which can be computed from their linear dimensions. Some of these are of the classical Kelvin guard-ring type, whereas others are of a new design.

The values of these small capacitance standards have been computed and measured by subdividing or stepping down from larger standards. The values of the larger capacitance standards were obtained by a well-established method in terms of resistance and time.

A comparison of the results obtained by direct computation and by subdivision is given.

\section{Conventional Kelvin Guard-Ring Standards of Capacitance}

The conventional Kelvin guard-ring construction was chosen for standards in the range of 0.1 to $5.0 \mu \mu \mathrm{f}$.

The design of the guard-ring capacitators constructed for this work is shown by the sectional drawing in figure 1. This design makes possible very precise construction. The guarded electrode, $G$, sometimes called the "island," is held rigidly and accurately centered in the guard ring, $G R$, by means of a Pyrex-glass disk, $D$. The glass disk is held in the guard ring by a spring clamping ring, $B$, shown in detail in figure 1 , which is tight-

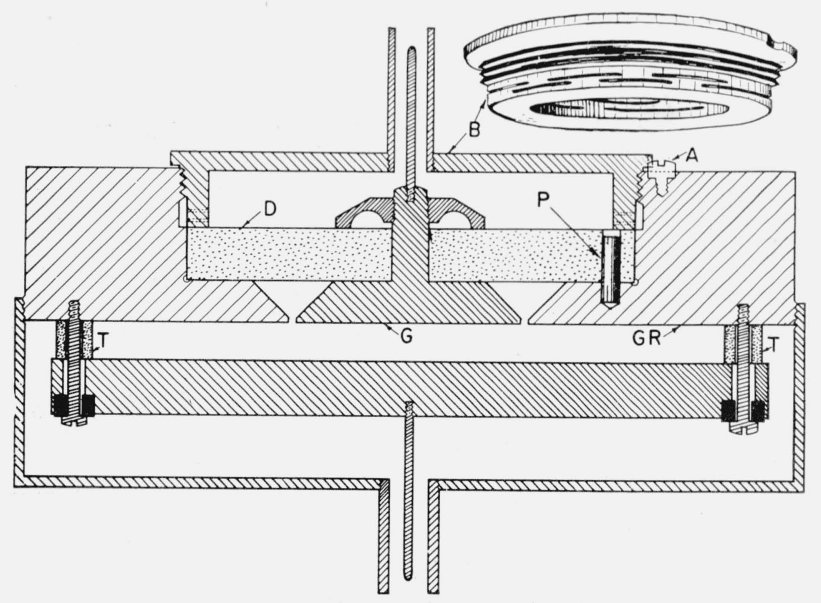

Figure 1. Kelvin guard-ring capacitor.

$D$, Pyrex glass disk; $P$, locating pin; $T$, spacers; $G$, guarded electrode or island; $G R$, guard-ring; $A$, locking screw; $B$, spring clamping ring. 
ened down to exert firm pressure on the glass disk. The head of a locking screw, $A$, engages a notch in the edge of the clamping ring so that the unit can be taken apart and reassembled with the same force on the glass disk. After a preliminary assembly, the common surface of the guard ring and the island is ground and lapped optically flat. The construction is such that the island with the Pyrex disk can be removed for cleaning and for correcting constructional imperfections, such as the removal of slight burs. It can then be reassembled with the surface of the island and guard ring in practically the same plane.

The island and guard ring are of the same material (brass or dural); the insulation is Pyrex glass. The island and glass disk, $D$, are fitted together with a ground joint and afterward machined together so that they are exactly concentric. The

TABLE 1. Dimensions and computed capacitance of Kelvin guard-ring capacitors

\begin{tabular}{|c|c|c|c|c|c|c|}
\hline Capacitor & $\begin{array}{l}\text { Nom- } \\
\text { inal } \\
\text { value }\end{array}$ & $\begin{array}{c}\text { Computed } \\
\text { capaci- } \\
\text { tance }\end{array}$ & $\begin{array}{c}\text { Diam- } \\
\text { ter } \\
\text { Island }\end{array}$ & $\begin{array}{l}\text { Diame- } \\
\text { ter hole }\end{array}$ & $\begin{array}{c}\text { Width } \\
\text { gap }\end{array}$ & $\begin{array}{l}\text { Length } \\
\text { spacers }\end{array}$ \\
\hline 3. & $\begin{array}{c}\mu \mu f \\
0.1\end{array}$ & $\begin{array}{l}a b s \mu \mu f \\
0.10134\end{array}$ & $\begin{array}{c}c m \\
1.0034\end{array}$ & $\begin{array}{c}\mathrm{cm} \\
1.0058\end{array}$ & $\begin{array}{c}c m \\
0.0012\end{array}$ & $\begin{array}{c}c m \\
0.6929\end{array}$ \\
\hline 1. & 1. 0 & 1.0019 & 2. 3945 & 2. 3997 & .0026 & .3991 \\
\hline $2 \ldots$ & 1.0 & 1.0014 & 2. 3900 & 2. 4119 & .0110 & .4006 \\
\hline $5 \ldots$ & 5.0 & 5. 0013 & 5. 9911 & 6. 0012 & .0050 & .5003 \\
\hline
\end{tabular}

recess in the guard ring for the glass disk is machined so that when heated to 15 or $20 \mathrm{deg} \mathrm{C}$ above room temperature, it will just slip onto the glass disk. Then starting at about $40^{\circ} \mathrm{C}$, the glass is lapped in place with very fine emery and the lapping continued until a temperature of 4 or $5 \mathrm{deg}$ above that of the room is reached. After washing away the abrasive, the glass disk fits in the brass ring at room temperature with practically no side shake. A hole is drilled in the edge of the glass and in the guard ring for a small dowel or locating pin, $P$, which is inserted after the assembly is made by a wringing motion. The high-voltage electrode is held at a fixed distance from the guard ring and island by three insulated screws that pass through three equal-length spacers of Pyrex-glass tubing, $T$, the ends of which are plane and parallel.

Four capacitors of this type have been constructed. The principal dimensions and computed capacitances are given in table 1 .

\section{Sources of Error in Guard-Ring Capacitors}

The factors that must be considered in guardring capacitors are 1. Errors in the mechanical dimensions; 2 . coplanarity of the guarded electrode and the guard-ring; 3 . eccentricity of the guarded electrode with respect to the guard-ring; 4. flatness of the electrodes; 5 . parallelism of guarded electrode and the high-voltage electrode; 6 . effect of the width of the gap between the guarded electrode and the guard-ring; 7 . sufficient width of guard-ring to avoid fringing.

The construction of the various parts of the guard-ring standards is such that accurate measurements of the parts can be readily made. The diameters of the guarded and guard electrodes were measured by a universal measuring microscope reading to $1 \mu$. The other dimensions needed were determined by comparison with Johansson gages by using a micrometer comparator that was sensitive to $0.1 \mu$. Based on the dimensional measurements, experience with the guard-ring type capacitors of $1.0 \mu \mu \mathrm{f}$ and larger indicates that an accuracy in the computed capacitance of better than 0.1 percent can be attained. This includes errors of measurement and the possibility of the inclusion of some foreign material between the parts in making the assembly.

Possibilities of error due to factors 2 to 5 listed above, are largely eliminated by the precision of the construction, and in no case has a correction been made for any of them. True coplanarity of island and guard-ring is the most difficult of the five to detect. An optical flat will show any tilting of the island with respect to the guardring but not necessarily an axial displacement with no tilting. The effect of displacing the guarded electrode in regard to the surface of the guard-ring is shown in figure 2. The change in capacitance for small displacements is approximately linear and from $1 \frac{1}{2}$ to 2 times as large as would be found by treating the displacement as if it were merely an increase in the distance between the plates.

For the $1-\mu \mu \mathrm{f}$ capacitor, the change in capacitance is 2.8 percent for a displacement of $60 \mu$. Hence for $1-\mu$ displacement, the error would be 0.05 percent. One-micron displacement on the 5 - $\mu$ f unit would cause a change in capacitance 


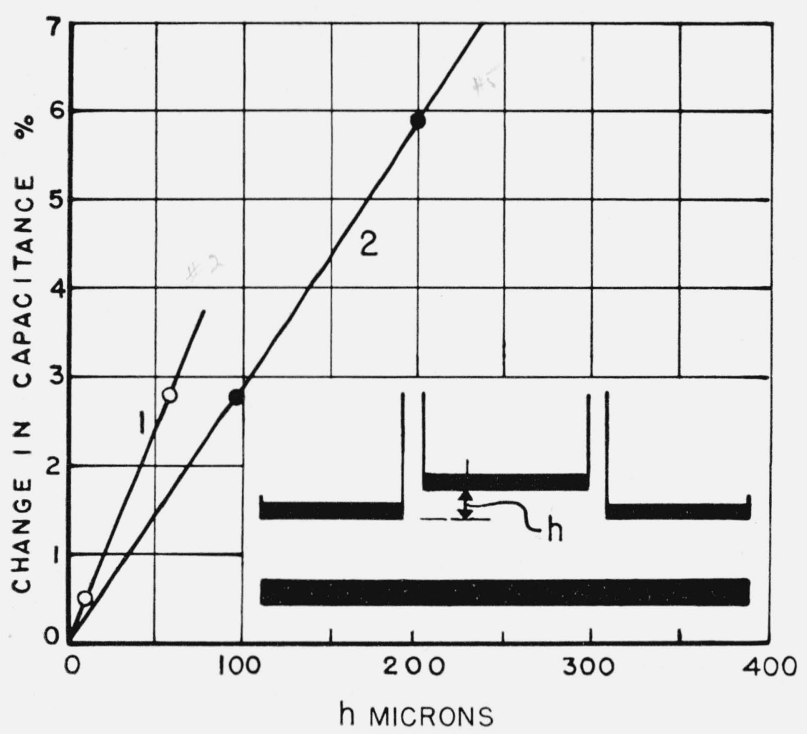

FIgURE 2. Graph showing measured change in capacitance of guard-ring capacitors when the guarded electrode is not coplanar with the guard-ring.

Curve 1 is for capacitor 2 in table 1 . Curve 2 is for capacitor 5 in table 1 .

of 0.03 percent. The difference in the level of the island and guard-ring of a capacitor that was taken apart and reassembled a large number of times was measured with an optical comparator. The displacement was found to be about 1 fringe, or $1 / 2 \mu$. The insignificance of the difference in level was verified by relapping the surface. Only a few strokes were required to bring the two surfaces to the same level. No measurable difference in capacitance was caused by the relapping.

The capacitance in electrostatic units of the Kelvin guard-ring capacitors in vacuum has ordinarily been computed by the simple formula.

$$
C=K\left(\frac{\bar{a}^{2}}{4 d}\right) .
$$

The computations have also been made by using the following unpublished formula by Chester Snow, which has an extra correction for the width of the gap:

$$
C=K\left[\frac{\bar{a}^{2}}{4 d}-\frac{\pi \bar{a}}{2}\left(\frac{a_{2}-a_{1}}{2 \pi d}\right)^{2} \operatorname{coth}\left(\frac{\pi \bar{a}}{d}\right)\right],
$$

where

$\mathrm{C}=$ capacitance in cos electrostatic units

$a_{1}=$ radius of the guarded electrode or island

$a_{2}=$ radius of the hole in the guard ring $\bar{a}=\left(a_{1}+a_{2}\right) / 2$

$d=$ separation of electrodes

$K=$ dielectric constant of air.

The correction for the width of the gap computed from eq 2, for the widest gap used, was only 1 part in 100,000 .

If the capacitance of a capacitor in electromagnetic units is taken as $1 /\left(2.99776 \times 10^{10}\right)^{2}$ times capacitance in electrostatic units, and the dielectric constant of air as $1.000567[1],{ }^{1}$ the simple formula (1), expressed in micromicrofarads, reduces to

$$
C=\frac{\bar{a}^{2}}{3.59259 d} .
$$

This formula has been used in computing the values in table 1 .

The width of the guard ring must either be wide enough to eliminate any measurable fringing, or some corrective device must be added, such as the system of guard hoops used by Brooks, Defandorf, and Silsbee [2] in the absolute electrometer, or a resistive shield of the type employed by Slonczewski [3]. Some experimental tests with these devices were made on $1.0-\mu \mu \mathrm{f}$ capacitor 2 , which was fitted with spacers $4.040 \mathrm{~cm}$ long, whereby its nominal value was changed to $0.1 \mu \mu \mathrm{f}$. This spacing was so large that some voltage-dividing device was necessary. It was accordingly fitted in succession with a system of guard hoops and a resistive shield. The guard-hoop system was made up of nine hoops spaced about $4 \mathrm{~mm}$ apart connected together by 1,000-ohm resistors between the hoops and also between the end hoops and the capacitor electrodes. The capacitor with guard hoops is shown in figure 3 . The resistive shield was a helix of 40 turns of advance wire, resistance $8,000 \mathrm{ohms,}$ wound inside a paper tube. Difficulty was encountered in getting the two ends of the helix to terminate exactly in the plane of the electrodes. Some interesting results of connecting these devices to a capacitor in different ways were obtained and are given in table 2. From these results it is evident that when a corrective device, such as a resistive shield or voltage-divider hoops, is used in a capacitor that has a large plate separation, the construction must be precise, because it then plays an important part in the capacitance. The lines

${ }_{1}^{1}$ Figures in brackets indicate the literature references at the end of this paper. 


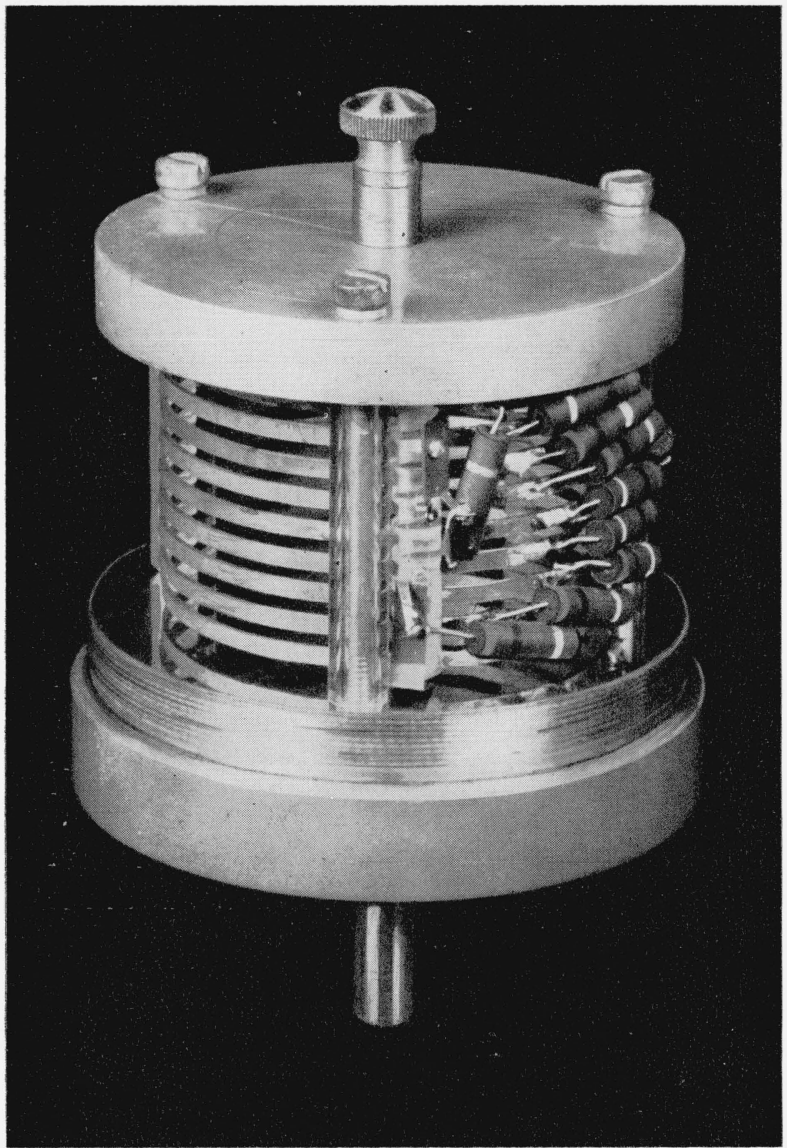

Figure 3. Capacitor 2 fitted with guard-hoop system.

of electrical force are ordinarily pictured as streaming in parallel lines normal to the two electrodes, and the hoop system as being simply a device for preventing the bulging of the lines at the edge of the plates. Experiments indicate that when the separation between the plates is very large the high-voltage plate plays a very small part in the capacitance. A shift in an axial direction of the hoop system of $0.5 \mathrm{~mm}$ caused a larger change in capacitance than a hole of a diameter equal to that of the island cut through the center of the highvoltage plate. Similar conclusions were reached in the experimental study of the absolute electrometer [2]. As new designs for absolute capacitors in the range of $0.1 \mu \mu \mathrm{f}$ and below have been developed, no attempt has been made to construct precision capacitors either with guard hoops or resistive shields. The values given in table 2 are not to be taken as indicating the accuracy that could be had by more careful construction because neither of the devices was precision made. The results given in table 2 , with the voltage-dividing system connected to one electrode only, indicate a method of testing, whether or not such a device is needed. If no change of capacitance is observed, whatever the manner of connecting the system, no corrective device is needed. To make this test, it is not necessary to construct an elaborate device, as a single metal ring, as shown in the inset of figure 4, will suffice. The results, which are selfexplanatory, are shown in figure 4.

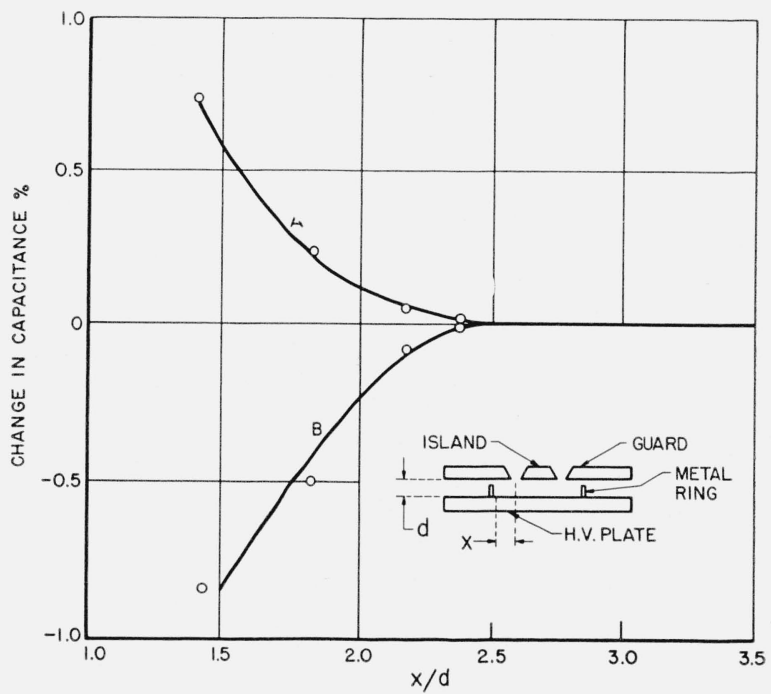

FIGURE 4. Curves showing the change in capacitance caused by fringing when a metal ring was in contact with either the guard-ring, curve $B$, or the high-voltage plate, curve $A$, of a guard-ring capacitor 1 of table 1 .

Four rings of different diameters were used, $d$ was constant.

TABLE 2. Results of tests under various conditions, with two voltage-dividing devices used to overcome fringing in a guard-ring capacitor

Computed capacitance (assuming no fringing): $0.099 \mu \mu \mathrm{f}$

Measured capacitance (without voltage dividing device): $0.093 \mu \mu \mathrm{f}$

\begin{tabular}{|c|c|c|}
\hline \multirow{2}{*}{$\begin{array}{l}\text { Manner of connecting voltage dividing device, } \\
\text { if any }\end{array}$} & \multicolumn{2}{|c|}{$\begin{array}{l}\text { Capacitance in micro- } \\
\text { microfarads with-- }\end{array}$} \\
\hline & $\begin{array}{l}\text { Resistive } \\
\text { shield }\end{array}$ & $\begin{array}{l}\text { Guard } \\
\text { hoops }\end{array}$ \\
\hline Properly connected to both plates... & 0.098 & 0.101 \\
\hline To guard ring only & .044 & .043 \\
\hline To high-voltage plate only ................ & .180 & .182 \\
\hline Floating (insulated from both plates) & .096 & .099 \\
\hline
\end{tabular}

\section{New Designs of Primary Capacitors of Very Low Value}

Below $0.1 \mu \mu f$, the classical guard-ring capacitor is not so suitable, because either the diameter of 
the island must be very small or the separation of the electrodes must be large.

For capacitance standards of $0.1 \mu \mu \mathrm{f}$ and smaller, two new capacitors, in which the guarded electrode is at the bottom of a recess, or well, in the guard electrode, have been developed. ${ }^{2}$ These are referred to in the paper as the "guard-well" type. This design permits the making of primary standards as small as desired in capacitance and at the same time keeping the linear dimensions large enough to be constructed and measured accurately.

Two forms of guard-well capacitors have been constructed. One form is shown in figure 5 and is referred to in this paper as the "rectangular type." The other form, referred to as the "circular type," is shown in figure 6 (a fixed capacitance unit) and figure 7 (a continuously variable capacitance unit).

As shown schematically in figure 5, the rectangular-type capacitor consists of a rectangular guarded electrode or island, $F$, which is at the bottom of a slot of depth $d$ and a high-voltage electrode, $E$, which is spaced a short distance, $c$, above the top of the slot. One standard was built to verify the formula developed by Chester Snow for a guard-well capacitor of the rectangular type. The construction and measurement of the dimensions of this capacitor are more difficult than for the circular ones shown in figure 6 , for which he later developed a precise formula. The mounting of the guarded electrode in the circular capacitor is identical with that of the guard-ring capacitor shown in figure 1. Actually, by the addition of an annular ring, $H$, of thickness, $d$, with plane parallel sides and a hole having a diameter slightly larger than the diameter of the island, the standard guard-ring capacitor shown in figure 1 can be converted to the new design shown in figure 6 .
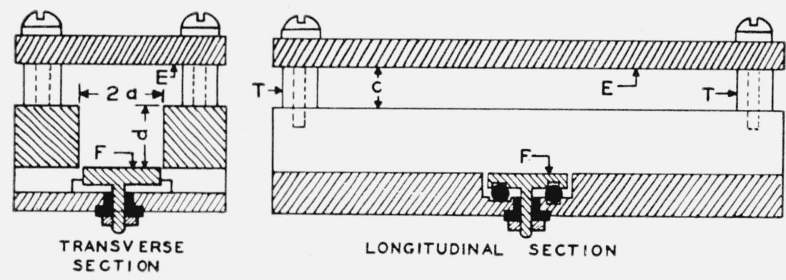

Figure 5. Rectangular type of guard-well cafacitor. $F$, guarded electrode.

2 The fundamental idea for this design was contributed by F. B. Silsbee, Chief, Division of Electricity and Optics. Formulas for computing the capacitance of these new designs have been derived by Chester Snow and will be published in the near future.

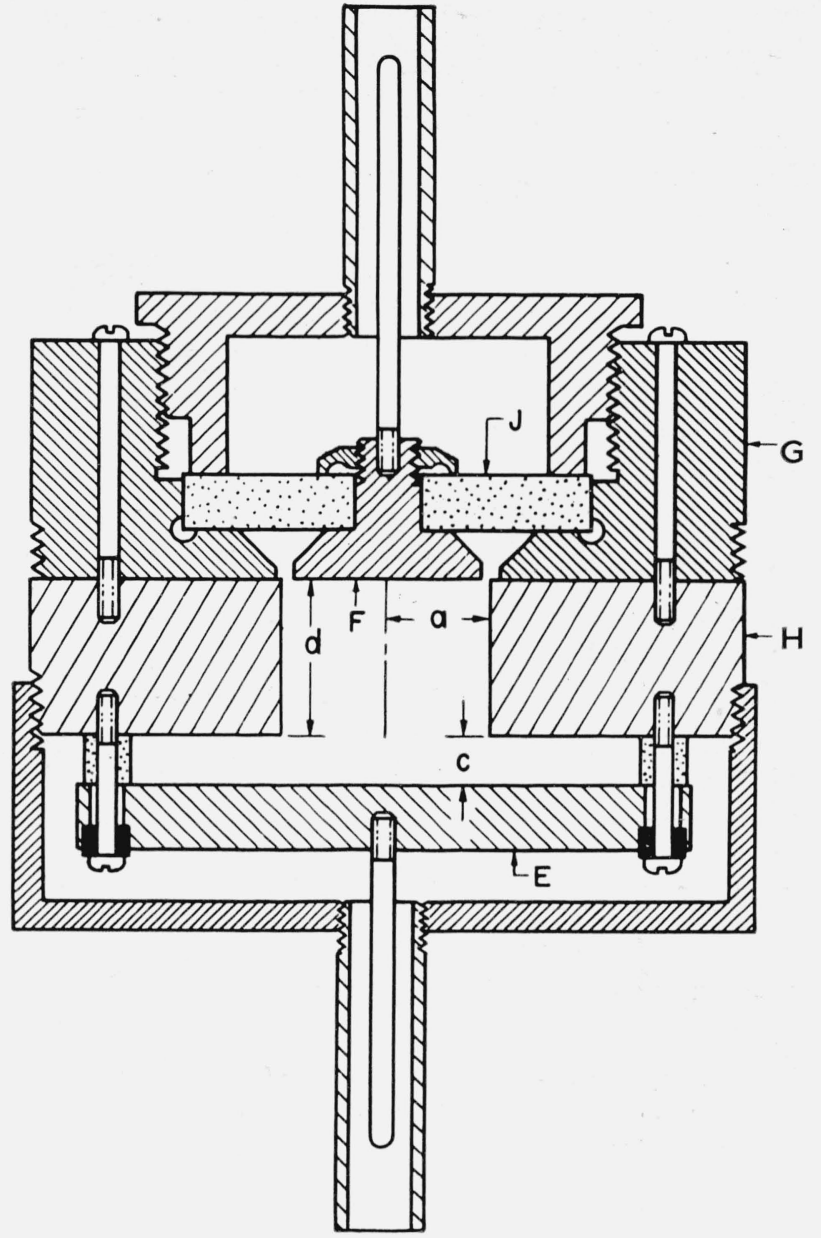

Figure 6. New type of primary capacitor.

This capacitor consists essentially of the parts of the guard-ring capacitor shown in figure 1 with the addition of the annular ring, $H$.

The dimensions of a circular capacitor, fitted with three annular rings, $H$, and giving nominal values of capacitance of $0.1,0.01$, and $0.001 \mu \mu \mathrm{f}$ are given in table 3 , along with the computed and measured values.

The depth, $d$, of each of the three rings was adjusted by trial until the measured capacitances were those given in the table. The measured values of capacitance of these three small units were obtained by subdividing a value of $1 \mu \mu \mathrm{f}$, which had been previously established. (The method of subdivision will be described later.)

After the units had been adjusted experimentally to have the measured values given in the table, under the heading of measured capacitance, their dimensions were used to compute their capacitances by the formula derived by Dr. Snow. A 


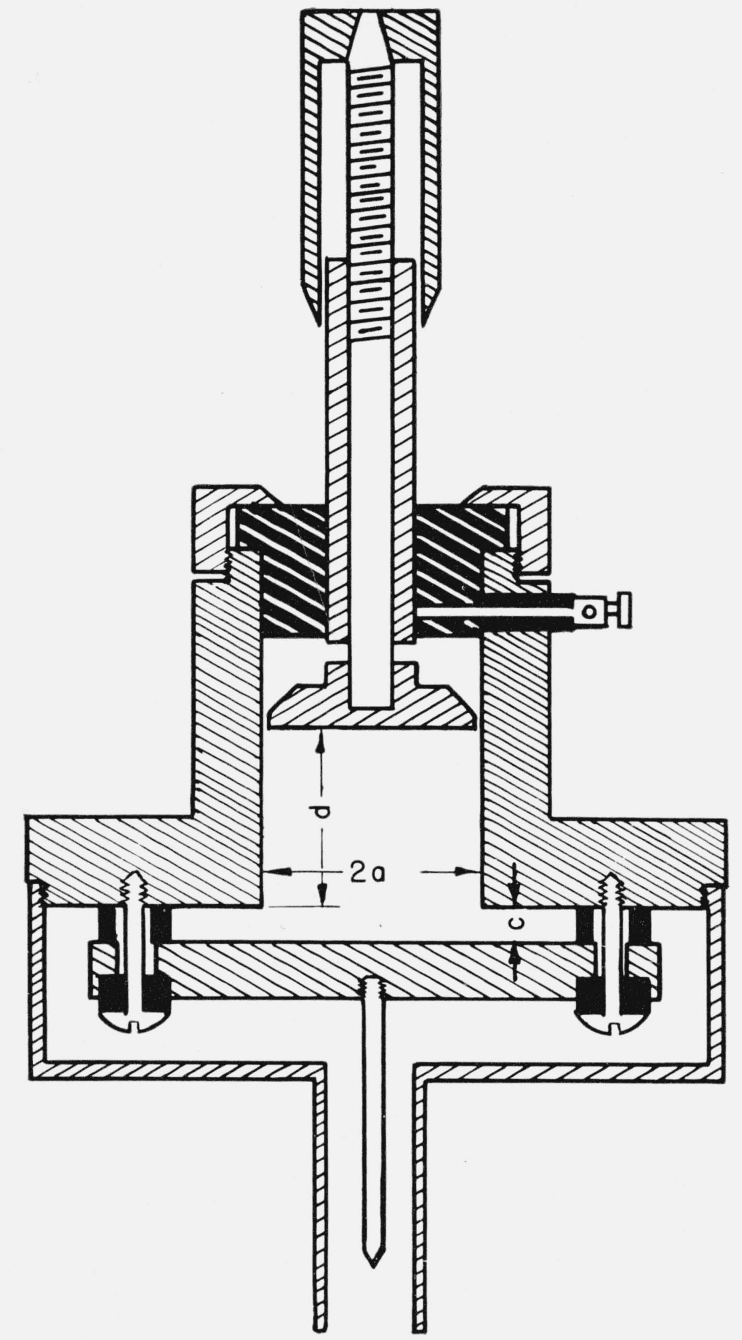

Figure 7. Continuously variable capacitor of the guardwell type.

The capacitor has a range from 0.1 to $0.001 \mu \mu \mathrm{f}$.

comparison of the measured and computed values of capacitance is a good indication of the accuracy obtained in subdividing $1 \mu \mu \mathrm{f}$. (See table 3).

TABLE 3. Dimensions of new circular type of primary standards of direct capacitance

\begin{tabular}{|c|c|c|c|c|c|}
\hline \multirow{2}{*}{$\begin{array}{c}\text { Nominal } \\
\text { capaci- } \\
\text { tance }\end{array}$} & \multicolumn{3}{|c|}{ Dimensions } & \multicolumn{2}{|c|}{ Capacitance } \\
\hline & a & c & d & Computed & Measured \\
\hline$\mu \mu f$ & $\mathrm{~cm}$ & $\mathrm{~cm}$ & $\mathrm{~cm}$ & $\mu \mu f$ & $\mu \mu f$ \\
\hline 0.1 & 1. 680 & .2098 & 1. $733_{1}$ & 0.09976 & 0.1000 \\
\hline .01 & 1. 680 & .2098 & $3.334_{2}$ & .009947 & .00997 \\
\hline .001 & 1. 680 & 2098 & 4. $928_{2}$ & .001016 & .00101 \\
\hline ..... & 1. 680 & .2098 & a 0 & 3.745 & - \\
\hline
\end{tabular}

- When $d=0$, the capacitor becomes a conventional Kelvin guard-ring type.
A variable model of the circular capacitor has been made, in which the low-voltage electrode is mounted on a micrometer screw, making the depth $d$ and therefore the capacitance, continuously variable. The range is from 0.1 to 0.001 $\mu \mu \mathrm{f}$ (see fig. 7).

The computed variations of capacitance with dimensions of a capacitor of this form is illustrated by the curve in figure 8 , from which it will be seen that a capacitance as small as desired can readily be obtained.

The formulas for computing the capacitance of both the linear and circular capacitors have been derived on the assumption that the gap between the island and the annular ring is infinitely small, that the edges of the hole in the annular guard ring are not rounded, and that the guard ring and high-voltage plate extend to infinity. Measurements on an experimental model show that the gap between the island and the annular ring can be as large as several thousandths of an inch, which was anticipated because the electric field is very weak in that vicinity, also that the highvoltage plate need extend over the edge of the annular ring, or the edges of the bars in the rectangular model, for a distance of only three or four times the length of the spacers used to separate the high-voltage plate from the ring or bars.

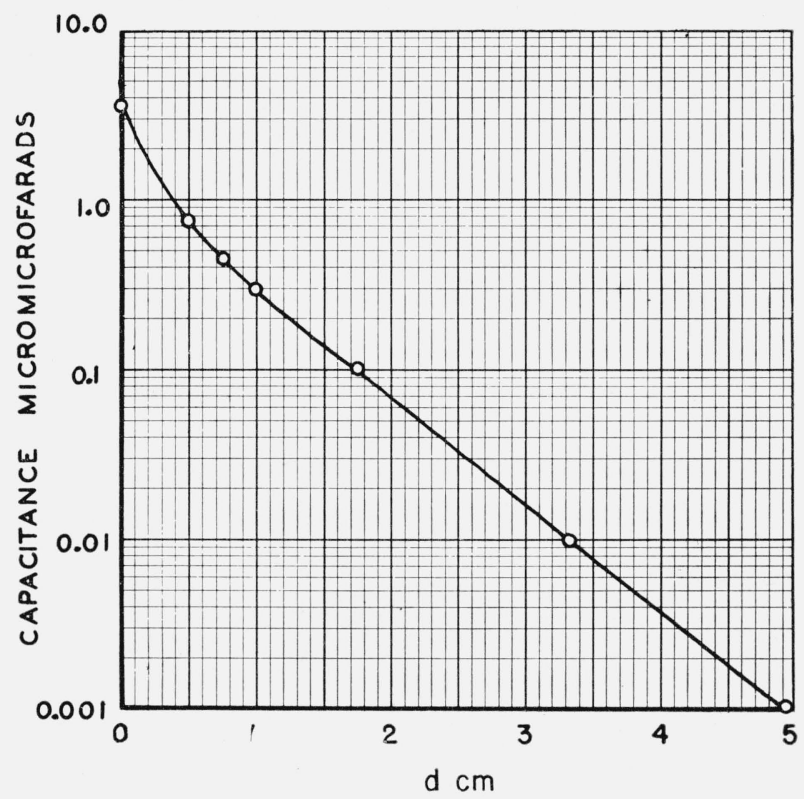

FiguRE 8. Graph showing change in capacitance with depth $d$ of the annular ring, $H$, plotted from data in table 3 and other computed values. 
A further increase in the size of the high-voltage plate has no measureable effect and is undesirable because it increases the capacitance to ground of the high-voltage electrode. The edges of the hole in the guard ring of the circular type and the edges of the bars in the rectangular type were rounded to a radius estimated to be $0.02 \mathrm{~mm}$ without any measurable effect on the capacitance. As this is more than is required to remove incidental burs, the rounding was carried no further.

Snow's formulas for computing the capacitance of the new designs are:

For the rectangular type, the coefficient of capacitance $C^{\prime}$ (per unit length of slot), is given by

$$
\pi C^{\prime}=\frac{1}{\gamma} \sum_{s=1}^{\infty} \frac{\left(1+\epsilon_{s}^{\prime}\right) \sinh \gamma \alpha_{s}^{\prime}}{\alpha_{s}^{\prime 2} \sinh (\beta+\gamma) \alpha_{s}^{\prime}}
$$

where $\cos \alpha_{S}^{\prime}=0$.

The coefficient $C$ for the circular type is given by

$$
\frac{C}{a}=\frac{1}{\gamma} \sum_{s=1}^{\infty} \frac{\left(1+\epsilon_{s}\right) \sinh \gamma \alpha_{s},}{\alpha_{s}^{2} \sinh (\beta+\gamma) \alpha_{s}}
$$

where $\alpha_{s}$ is the $s^{\text {th }}$ positive root of the Bessel function $\mathrm{J}_{0}(\alpha)=0 ; a$ is the radius of the cylindrical hole (or the half-width of the slot); $C$ and $d$ have dimensions indicated in figures 5 and $6 ; \gamma=c / a$ and $\beta=d / a$; $\epsilon_{s}\left(\right.$ and $\left.\epsilon_{s}^{\prime}\right)=0$ except $\epsilon_{1}\left(\right.$ or $\left.\epsilon_{1}^{\prime}\right)$.

$$
\boldsymbol{\epsilon}_{1}=\frac{2}{\pi}\left(\frac{\gamma \alpha_{1}}{\pi}\right)^{2}\left[\sum_{k=1}^{n} P_{k}+R_{n+1}\right]
$$

where

$$
P_{1}=\frac{S\left(\frac{\gamma \alpha_{1}}{\pi}\right)-\left(\frac{\gamma \alpha_{1}}{\pi}\right)^{2} T\left(\frac{\gamma \alpha_{1}}{\pi}\right)}{\alpha_{1}\left(\operatorname{coth} \gamma \alpha_{1}+\operatorname{coth} \beta \alpha_{1}\right)},
$$

and for $k>1$,

$$
\begin{aligned}
P_{k}= & \frac{1}{\alpha_{k}\left(\operatorname{coth} \gamma \alpha_{k}+\operatorname{coth} \beta \alpha_{k}\right)} \\
& \left\{S\left(\frac{\gamma \alpha_{k}}{\pi}\right)-\frac{\alpha_{1}^{2}}{\alpha_{k}^{2}-\alpha_{1}^{2}}\left[S\left(\frac{\gamma \alpha_{1}}{\pi}\right)-S\left(\frac{\gamma \alpha_{k}}{\pi}\right)\right]\right\},
\end{aligned}
$$

where $\alpha_{k}$ is the $k^{\text {th }}$ positive root of the Bessel function $J_{0}(\alpha)=0$.

$$
S(u)=\sum_{n=1}^{\infty} \frac{1}{n\left(n^{2}+u^{2}\right)},
$$

and

$$
T(u)=\sum_{n=1}^{\infty} \frac{1}{n\left(n^{2}+u^{2}\right)^{2}} .
$$

For values of $u$ less than $1, S(u)$ can be evaluated by

$$
\begin{aligned}
S(u)= & 1.20206-1.03693 u^{2}+1.00835 u^{4}- \\
& 1.00201 u^{6}+1.00049 u^{8}-u^{10} \sum_{n=1}^{\infty} \frac{1}{n^{11}\left(n^{2}+u^{2}\right)},
\end{aligned}
$$

and $T(u)$ by

$$
\begin{aligned}
T(u)= & 1.03693-2.01670 u^{2}+3.00602 u^{4}- \\
& 4 u^{6} \sum_{n=1}^{\infty} \frac{1}{n^{7}\left(n^{2}+u^{2}\right)^{2}}-3 u^{8} \sum_{n=1}^{\infty} \frac{1}{n^{9}\left(n^{2}+u^{2}\right)^{2}} .
\end{aligned}
$$

The remainder, $R_{n+1}$, is computed by

$$
\begin{aligned}
R_{n+1} \equiv & \sum_{k=n+1}^{\infty} P_{k} \approx \frac{1}{4 \pi\left(1+\operatorname{coth} \gamma \alpha_{n+1}\right)} \\
& \left\{\frac{0.1544+\log \left(1+x_{n}^{2}\right)}{x_{n}^{2}}+2 \log \left(\frac{1+x_{n}^{2}}{x_{n}^{2}}\right)\right\},
\end{aligned}
$$

where $x_{n}=\gamma\left(\frac{\alpha_{n}}{\pi}+\frac{1}{2}\right)$. (Computations were made with $n=4$ ).

In the case of $\epsilon_{1}^{\prime}$, the formula is the same except that the $n^{\text {th }}$ root $\alpha_{n}$ of $J_{0}(\alpha)=0$ is replaced by

$$
\alpha_{n}^{\prime}=(2 n-1) \frac{\pi}{2},
$$

the $n^{\text {th }}$ root of $\cos \alpha=0$.

\section{Auxiliary Tools}

Several auxiliary tools were found convenient for use in measuring the small capacitors. Two of these will be described. One was a low-range continuously variable capacitor by which small differences between units could be taken up. The other was a "decade" capacitor consisting of small sections by which an accurate step-up from 0.1 to $1 \mu \mu \mathrm{f}$ could be achieved.

The design of this variable low-range capacitor is an adaptation of that described by G. Zickner [4]. This capacitor, figure 9, consists of two active electrodes shielded by a third electrode and separated by a fixed plate or septum connected to the shield and in which a semicircular opening is cut. The capacitance is varied by a rotatable plate also connected to the shield that covers part or all of the opening in the septum. The advantage of this type of unit is that the minimum direct capacitance is exactly zero, the scale is linear, and the full-scale value can be made as 


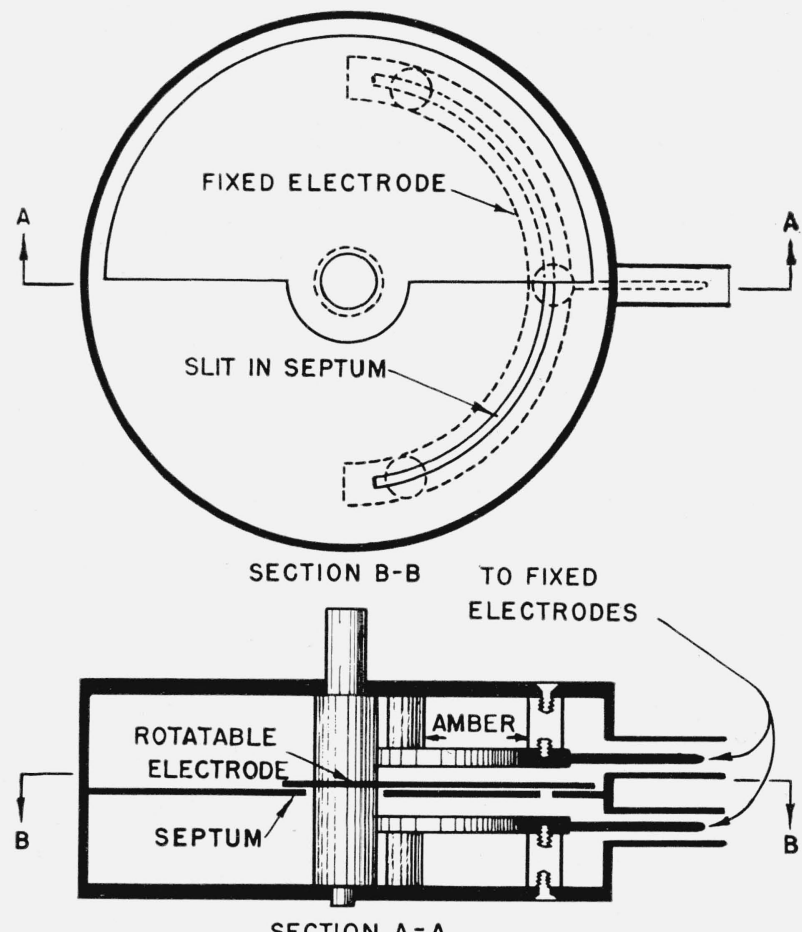

SECTION A-A

Figure 9. Continuously variable low-range capacitor (schematic).

small as desired by using a narrow annular slit in the septum in place of the semicircular opening used by Zickner. The capacitance range depends upon the width of the slit and the spacing of the fixed electrodes. The construction of the Zickner-type capacitor started with the chassis and worm gearing of a variable capacitor. The group of stator plates was replaced by two 1/8-in.thick full circular brass plates, which served as supports for the fixed electrodes, between which a thin brass plate, which fuctioned as a septum, was interposed. In this plate a 4-mm annular slit was cut with the axis of the rotor as its center. The slit extended over an arc of about $150^{\circ}$. In place of the semicircular plates used by Zickner, the fixed electrodes were, in this case, semiannular rings of brass about $1.5 \mathrm{~cm}$ wide. A single semicircular plate on the rotating shaft, which slid in close contact with the septum, served to vary the area of the opening and hence the capacitance.

The 4-mm slit in the septum resulted in a variable capacitor having a range from 0 to $0.3 \mu \mu \mathrm{f}$. One division on the scale is equivalent to 0.000170 $\mu \mu \mathrm{f}$.
In addition, a second unit was built in the same chassis having dimensions whereby a range of capacitance from 0 to $5.8 \mu \mu \mathrm{f}$ was obtained. The change in capacitance per division of the larger range is $0.00292 \mu \mu \mathrm{f}$.

A capacitance of $0.1 \mu \mu \mathrm{f}$ was the smallest value for which it seemed desirable to make a standard of the guard-ring type and about as large as practical for the guard-well type. An accurate independent means of stepping up from 0.1 to 1.0 $\mu \mu \mathrm{f}$ seemed desirable. For this purpose a decade capacitor was designed that is thought to be free from any "switching" errors. It consists of five units: two of $0.1 \mu \mu \mathrm{f}$, two of $0.2 \mu \mu \mathrm{f}$, and one of $0.4 \mu \mu \mathrm{f}$. These are symmetrically arranged around and connected to central coaxial terminals, as shown in figure 10 .

Each unit of the decade, as shown by the cutaway part, consists of a pair of plates insulated

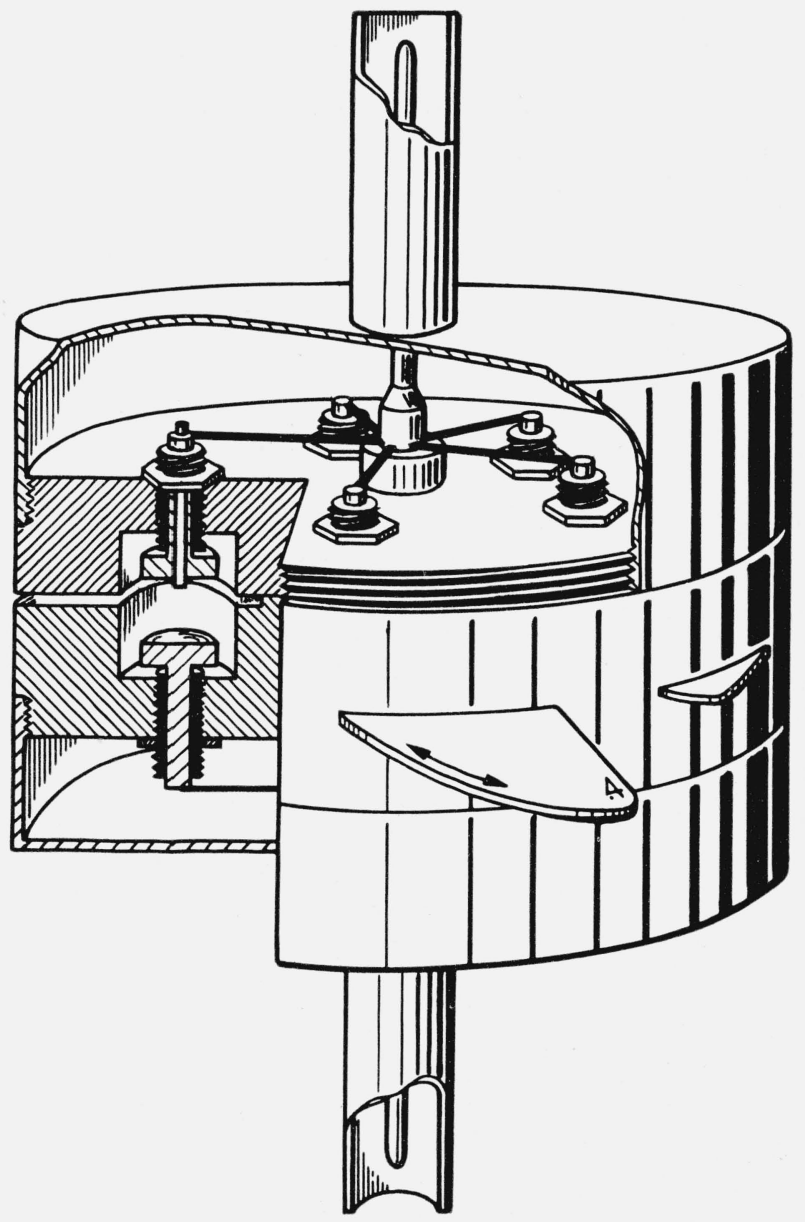

Figure 10. Decade capacitor.

Vernier screw shown in upper electrode. 
from the housing and a pivoted shutter that is connected to the housing. When closed, this shutter completely isolates one terminal from the other so that the capacitance of the unit is strictly zero. The groove for the shutter is shown in the cutaway part, but the shutter is omitted. On the right are shown two shutters, the one for the 0.1 $\mu \mu \mathrm{f}$ unit closed, and the other for the $0.4 \mu \mu \mathrm{f}$ unit open. A rough adjustment of the capacitance of a unit of this type can be readily made by adjusting the distance between the plates and then a very close adjustment by means of the vernier screw in the center of one of the electrodes, a detail of which is shown in the upper electrode. The units were thus adjusted to be equal or exact multiples of each other within the limits of sensitivity of the bridge used for measuring their capacitance and have held this adjustment for over a year.

\section{Bridges}

It is not within the scope of this paper to discuss the methods of measuring direct capacitance. Since all of the bridges used have either been adequately described elsewhere or are commercially available equipment, the discussion will be largely confined to factors that affect the accuracy of measurement and methods of using the bridges in the measurement of the various capacitors.

For intercomparing the standards of $5 \mu \mu \mathrm{f}$ and lower, the instrument found most useful was a Western Electric Direct Capacitance Test Set Model D-160936. This set, shown schematically

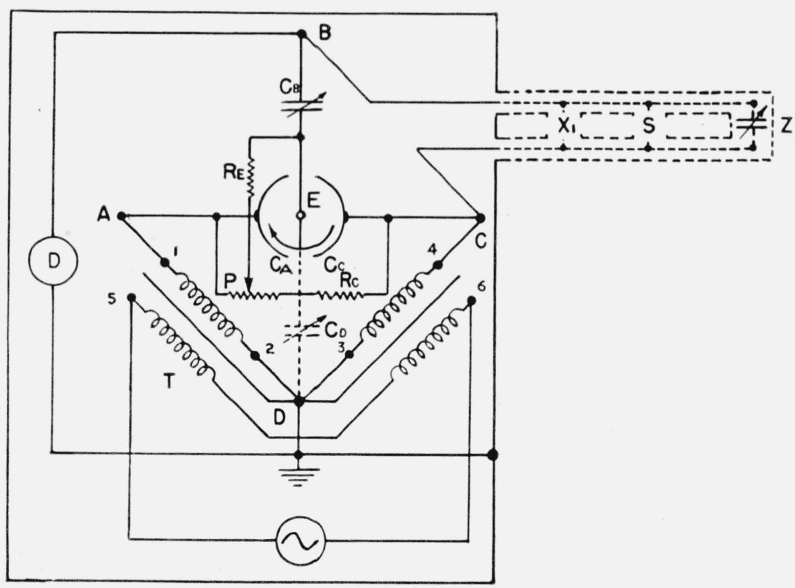

Figure 11. Schematic sketch of Western Electric Direct Capacitance Test Set Model D-160936 showing method of connecting capacitors in parallel. in figure 11, consists of an alternating-current bridge built into a cabinet complete with an oscillator and tuned detector working at a fixed frequency of $465 \mathrm{kc} / \mathrm{sec}$. The ratio arms $A D$ and $D C$ are of the inductive type, very closely coupled. Special conductance and capacitance units are provided that are direct reading for capacitances from 0.00005 to $110 \mu \mu$ f and for conductances from 0 to $10 \mu$ mho.

The residual admittances fall either across the detector corners of the bridge, so that they do not enter into the balance equation, or across the ratio arm $C D$. If the coupling between the ratio arms were 100 percent, no error would be caused by the burden on one arm. Since 100-percent coupling cannot be quite obtained, a slight error is caused by the unequal loading of the ratio arms. In all measurements, the residual admittances across the $C D$ arm were either small or were kept practically constant during a given measurement so that no appreciable error was introduced from this source.

When two or more capacitors were connected in parallel, coaxial leads were used to connect the units to both terminals of the test set. The test set was not designed to be a precision instrument, but it has the stability and sensitivity necessary for the measurement of very small capacitors. In this work the test set was used merely as a balance to determine the equality of two capacitances by a substitution method. For this purpose it was well suited. The only alteration made in the test set was in the detector tuning unit, which was changed so that it could be tuned with a larger than normal capacitance to ground at the $B$ terminal.

The small primary capacitance standards were measured by subdividing a $1,000-\mu \mu \mathrm{f}$ variable standard capacitor in a Schering bridge.

The method is old and in general use for calibrating variable capacitors by stepping up, subdividing, etc. An unknown three-terminal capacitor, $x$, was compared with a calibrated variable standard having a range of capacitance of 1,000 $\mu \mu \mathrm{f}$ between 100 and 1,100 scale divisions. This difference in capacitance of approximately 1,000 $\mu \mu \mathrm{f}$ was accurately known, having been predetermined in the well-known Maxwell commutator bridge [7] in terms of resistance and time with an accuracy of about 0.01 percent.

The standard and the unknown, which was a three-terminal variable with a full-scale range of 
TABLE 4. Value of 0.1 micromicrofarad unit of decade capacitor in terms of various small primary capacitance standards and from Maxwell commutator bridge data

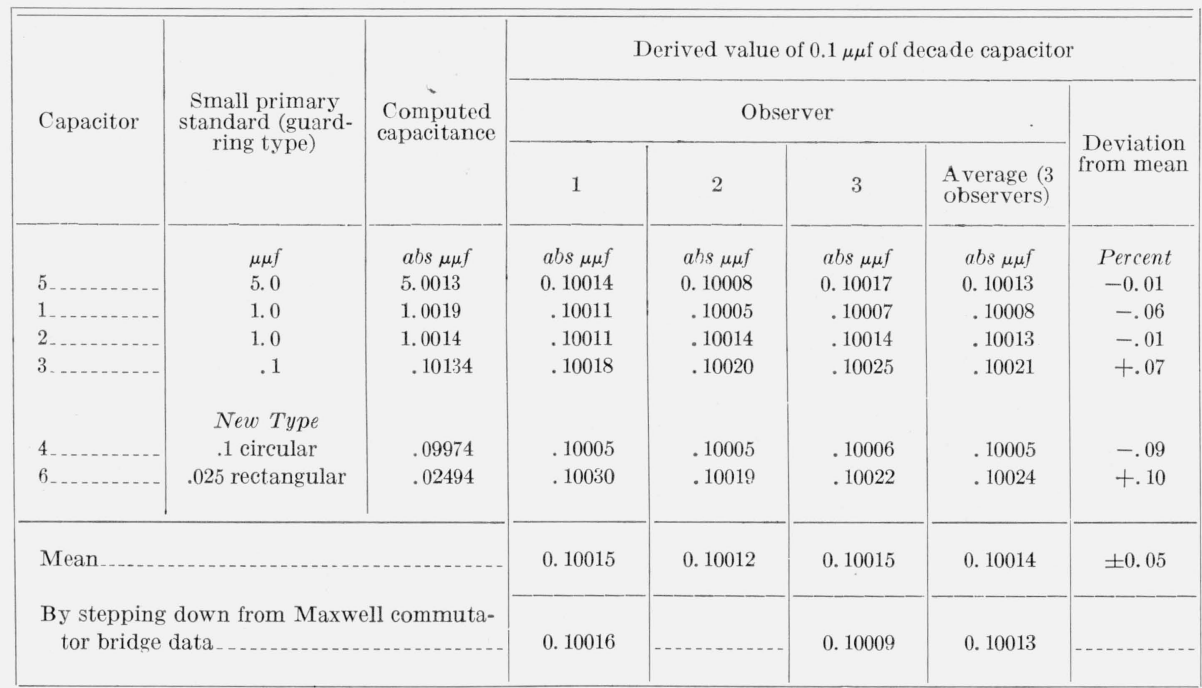

$100 \mu \mu \mathrm{f}$, were connected in parallel in the measuring arm of the bridge.

The change-of-standard method was employed for determining the unknown direct capacitance in the following manner: Starting with the standard set on the 100 scale point and with the unknown capacitor connected, the bridge is balanced holding the standard and unknown fixed. The unknown is then disconnected and the bridge rebalanced by increasing the standard. Leaving the standard fixed at this new position, the above procedure was repeated so that the value of the unknown was transferred to the standard in 10 additive steps, at the end of which addition the standard scale reading was very nearly 1,100 .

Normally the value of the standard will not be exactly 10 times the unknown. Since in our case both were calibrated variable capacitors, the difference could be read on either instrument. The difference, $\Delta$, was usually so small that a precise calibration of the scale used to read the difference was not important.

If $y=$ capacitance difference on the standard between scale points 100 and 1,$100 ; x=$ capacitance of unknown; $y-10 x=\Delta$; then $x=Y--\Delta / 10$. The above procedure was repeated to subdivide the $100-\mu \mu \mathrm{f}$ variable standard and finally a $10-\mu \mu \mathrm{f}$ variable standard both of which were of the three-terminal type.

In subdividing the $10-\mu \mu \mathrm{f}$ variable, the $1-\mu \mu \mathrm{f}$ and the 5 - $\mu \mu \mathrm{f}$ primary standards were used as unknowns, and their capacitances were thus ob- tained in terms of a capacitance difference of $1,000 \mu \mu f$ measured on a variable capacitor in the Maxwell commutator bridge.

For measuring secondary units of $5 \mu \mu \mathrm{f}$ and larger, a calibrated variable capacitor can be used as a satisfactory reference standard. The calibration of a secondary capacitor by using the Schering bridge has been made both by stepping up from the 5 - $\mu \mu \mathrm{f}$ guard-ring capacitor and also by stepping down from a $1,000-\mu \mu f$ variable capacitor, which had been measured in a Maxwell commutator bridge. The agreement between the values by the two methods was well within 0.1 percent.

The results given in table 4 indicate that a capacitance of $0.1 \mu \mu \mathrm{f}$ can be realized, with an accuracy of about 0.1 percent, either from absolute standards or by methods of subdividing large units. Standards 3 and 6 are considered to be the least reliable of the group. Omitting the values obtained from standards 3 and 6 , the mean value of the $0.1-\mu \mu \mathrm{f}$ fixed standard is lowered by 0.04 percent, or to $0.10010 \mu \mu \mathrm{f}$, which is believed to be its most probable value.

\section{Summary and Conclusions}

A number of primary standards of capacitance have been built, the construction being such that their capacitance should remain permanent over long periods. A number of auxiliary tools have been made to use in intercomparing the primary 
standards and in comparing primary standards with unknown secondary standards.

The methods of measuring the primary standards are described, including the transfer of a capacitance difference on a large variable capacitor measured in the Maxwell commutator bridge to the Schering bridge where this capacitance difference is subdivided and compared with some of the newly designed low-capacitance standards.

The capacitance values of the primary standards have been computed from their dimensions.

Results of measurements by the various test methods and a comparison with the computed values of the standards is given.

From measurements and intercomparisons on a number of small capacitance units, it seems that an accuracy of about 0.1 percent can be obtained in the calibration of capacitors from $5 \mu \mu \mathrm{f}$ to perhaps as low as $0.1 \mu \mu f$. For $0.01 \mu \mu \mathrm{f}$, the accuracy is probably \pm 0.5 percent, and for 0.001 $\mu \mu \mathrm{f}$ about \pm 2 percent.

The computed capacitance of the smaller primary standards agrees within about 0.1 percent with the values obtained by a method of subdivision from larger units, the values of which were determined by bridge methods in terms of resistance and time.

The Bureau is now equipped with a set of reference standards of capacitance in the range from 0.001 to $100 \mu \mu f$. Test methods have been de- veloped so that secondary standards of equivalent range can be tested and certified with the precision needed to determine the interelectrode capacitance of electron tubes.

The authors express their appreciation to R. L. Driscoll for making some of the computations; to Thelma Hollis for many of the electrical measurements; to A. H. Scott for the Schering bridge measurements; and L. P. Slivka for his painstaking work in the construction of several of the capacitors.

\section{References}

[1] L. G. Grant and D. L. Woernley, Phys. Rev. [2], 69, 101 (Jan.-June 1946).

[2] H. B. Brooks, F. M. Defandorf, and F. B. Silsbee, J. Research NBS 20, 253 (1938) RP1078.

[3] T. Slonczewski, Rev. Sci. Instr. 18, 848 (Nov. 1947).

[4] G. Zickner, Elek. Nachr-Tech. 7, 443 (1930); B. Hague, AC Bridge methods, 4th ed., p. 344 (Pitman Publishing Corp., New York, N. Y., 1938).

[5] U. S. Patent 2309490 (Jan. 26, 1943); U. S. Patent 2326274 (Aug. 10, 1943).

[6] ASTM Standards, part III-B Supplement, p. 109 (1947).

[7] H. L. Curtis and C. Moon, BS Sci. Pap. 22, 487 (1927) S564; J. C. Maxwell, Electricity and magnetism 1, ed. 2, Art 771 (The Clarendon Press, Oxford, London, 1892).

Washington, June 2, 1948. 